\title{
Güneş Enerjisi Santrallerinin Arazi Kullanımına Etkisi ve Sonuçları: Osmaniye Örneği
}

\author{
Faz1l Nacar ${ }^{1 *}$ \\ 1* Osmaniye Korkut Ata Üniversitesi, Mühendislik Fakültesi, Harita Mühendisliği Bölümü, Osmaniye, Türkiye
}

(2nd International Conference on Access to Recent Advances in Engineering and Digitalization (ARACONF)-10-12 March 2021)

(DOI: 10.31590/ejosat.899350)

ATIF/REFERENCE: Nacar, F. (2021). Güneş Enerjisi Santrallerinin Arazi Kullanımına Etkisi ve Sonuçları: Osmaniye Örneği. Avrupa Bilim ve Teknoloji Dergisi, (24), 98-105.

$\ddot{O} \mathbf{z}$

Türkiye'de yenilenebilir enerji kaynaklarına verilen önem çerçevesinde, Hidroelektrik ve rüzgâr enerji santralleriyle başlayan süreç güneş enerjisi santralleriyle sürmektedir. Hidroelektrik santralleri ve rüzgâr enerjisi santral tesisleri, güneş enerjisi santrallerine (GES) göre daha az arazi planlama mevzuatı kapsamına girmekte, GES tesisleri araziye yayıldığından geniş arazi parçalarının kullanımını gerektirmektedir. Bu sebeple birçok kamu kurumunu ilgilendiren bir proje çalışmasıdır. Ülkemizde GES yatırımlar devlet tarafından teşvik edilmekte ve enerji alım garantisi verilmektedir. Bu nedenle özel sektörde bu konuya ağırlık vermekte yatırımlarını artırmaktadır. Bu çalışmada, Doğu Akdeniz bölgesinde Osmaniye'deki GES projeleri incelenmiştir. Arcgis programı kullanılarak, GES kurulumu tamamlanmış parsellerin İlçe bazlı Coğrafi Bilgi Sistemleri (CBS) veri tabanı oluşturulmuş ve arazi kullanımda oluşan değişimler izlenmiştir. Osmaniye'deki GES potansiyelinin kuruluma oranla çok fazla olduğu görülmektedir. Bu çalışmaya göre kıraç arazi için Osmaniye ilinde elde edilen tarımsal gelirin, GES tesisinden elde edilecek kira gelirine göre çok düşük olduğu belirlenmiş̧ir.

Anahtar Kelimeler: GES, Arcgis, Arazi Kullanımı, Osmaniye, CBS

\section{The Effects of Solar Energy Power Plants on Land Use and the Results: Case of Osmaniye}

\begin{abstract}
Turkey's important renewable energy sources begin with solar power plants, hydroelectric and wind power plants. Hydroelectric and wind power plant facilities fall under the scope of land planning legislation less than solar power plants (SPP), and SPP facilities require wide areas. Thus, this project study concerns many public institutions. In Turkey, SPP investments are supported by the state, and energy purchase guarantee is provided. Therefore, the private sector focuses on increasing their investments.

In this study, SPP projects in Osmaniye have been examined. District-based Geographical Information Systems (GIS) database was created for competed SPP setup parcels using the Arcgis program, and the changes in land use were monitored. It is seen that the SPP potential in Osmaniye is much higher than the establishment. According to this study, it was determined that the agricultural income obtained in Osmaniye for the barren land is lower than the rental income of SPP facility.
\end{abstract}

Keywords: SPP, Arcgis, Land Use, Osmaniye, Geographical Information Systems

\footnotetext{
*Sorumlu Yazar: fazilnacar@,osmaniye.edu.tr
} 


\section{Giriş}

2014 yılından sonra Güneş enerjisi pazarında yüzde 25 civarında büyüme olmuştur. Güneş enerjisi kapasitesi 2015 yılındaki 50 GW'lık artışla küresel ölçekte toplam $227 \mathrm{GW}$ kapasiteye ulaşılmıştır. Avrupa güneş enerjisi kurulu gücünde kapasite olarak Asya ve Kuzey Amerika 'nın önünde yer almaktadır. En yüksek fotovoltaik güneş sistemi kapasitesi sırasıyla Çin, Almanya, Japonya, ABD ve İtalya'ya aittir.(Karagöl \& Kavaz, 2017; Kern \& Trieb, 2015; Taktak \& Mehmet, 2018)

Çevrenin korunması, iklim değişikliğinin oluşturduğu zararların azaltılması, enerji üretimi ve tüketimi kaynaklı çevresel sorunların giderilmesi tüm insanların sorumluluğundadır. $\mathrm{Bu}$ nedenle, düşük çevresel etkiye sahip sürdürülebilir ve yenilenebilir enerji kaynakları bulmak ve bu konuda yeni teknolojiler geliştirmek zorunlu hale gelmiştir. Güneş enerjisi bu açıdan önem kazanmıştır.(Komitesi, 2009; Taktak \& Mehmet, 2018; Varınca \& Varank, 2005)
Kyoto Protokolü, imzacı ülkeleri fosil yakıt bağımlılıklarını azaltmaya zorlayan bir dizi yaptırım getirmektedir. Ayrıca yenilenebilir enerji ve çevre dostu teknolojilerin kullanımının artırılmasını ve bu yönde araştırmaların teşvik edilmesini desteklemektedir .(Bahnemann, 2004; Güçlüer \& Batuk, 2011; Şahin, 2009)

Güneş enerjisi diğer yenilenebilir enerji kaynaklarına göre daha kolay yaygınlaşacak özelliklere sahiptir. Diğer enerji kaynaklarına kıyasla, aşırı kurulum maliyetleri ve düşük verimlilik faktörü gibi bazı teknolojik ve ekonomik zorlukların aşılması, güneş enerjisini gelecekte daha çekici hale getirecektir. Türkiye'nin güneş enerjisi potansiyeli uygun olmasına rağmen yeterince yararlanılmamaktadır.(Bahnemann, 2004; Taktak \& Mehmet, 2018; Winston \& Hinterberger, 1975)

Güneş enerjisi santrallerinde, birim alandan elde edilen enerjinin miktarı ile arazinin büyüklüğü arasında sıkı bir ilişki vardır. Arazi ne kadar büyük ise kurulu güçte o kadar fazla olur. Diğer santraller ile karşılaştırıldığında, güneş enerjisi santrallerinin kurulumu için daha geniş araziler gerekmektedir.(SARSICI,

Tablo 1. Enerji Üretim Kategorilerine Göre Arazi Kullanım Miktarları(SARSICI, 2020)

\begin{tabular}{|l|c|}
\hline Santral Türü & Arazi Kullanımı (m²/GWs) \\
\hline Hidroelektrik Santrali (Baraj Tipi) & 2350 \\
\hline Isıl Güneş Santrali & 370 \\
\hline Fotovoltaik Güneş Santrali & 340 \\
\hline Doğalgaz Santrali & 320 \\
\hline Kömür Santrali (Yüzeysel Madencilik) & 240 \\
\hline Nükleer Santral & 130 \\
\hline
\end{tabular}

Uydulardan ve bilgi teknolojilerinden elde edilen görüntülerde yaşanan hızlı gelişmeler, Uzaktan Algılama ve Coğrafi Bilgi Sistemlerinin (CBS) gelişimini etkilemiştir.(GEYMEN, 2016; Kaya \& Toroğlu, 2015). Bu sistemlerin hızlı ve güvenilir yapısı, dünyada ve ülkemizde Uzaktan Algılama ve CBS teknikleri kullanılarak su havzalarında arazi kullanım değişiklikleri konusunda detaylı çalışmalar yapılmasına neden olmuştur.(AKBULAK et al., 2008; Dewan \& Yamaguchi, 2009; Fatih \& Karatepe, 2012; GEYMEN, 2016; Gürbüz et al., 2012; Shalaby \& Tateishi, 2007; Wu et al., 2006)

Konya ili Çumra ilçesinde güneş enerjisi santrali kurulabilecek alanların belirlenebilmesi amacıyla bir ÇKKV (Çok Kriterli Karar Verme ) modeli geliştirilmiştir. Elde edilen sonuçlar doğrudan seçilen kriterler ile ilişkilidir.(Mevlüt, 2017)

Seçilen yerleşim alanlarına olan uzaklık, eğim, arazi kullanımı, trafo merkezi ve iletim hatlarına olan uzaklık, yol ve demir yoluna uzaklık kriterleri dünyada daha önce yapılan benzer çalışmalara göre seçilmiş ve değerlendirilmiştir.(Sánchez-Lozano et al., 2013; Tahri et al., 2015; Watson \& Hudson, 2015; YALÇIN \& Mustafa, 2019)

Çalışma bölgesinde eğim, arazi kullanımı, akarsulara uzaklık, göllere uzaklık, yol ve demir yollarına uzaklık, enerji nakil hatlarına uzaklık olmak üzere altı kriter belirlenmiş ve Bulanık Analitik Hiyerarşi Prosesi kullanılarak kriterler ağırlıklandırılmış , uygun olmayan alanlar belirlenmiş ve kalan alanların uygunluk seviyeleri tespit edilmiştir.(KOCA \& UZAR)

GES projesi için en uygun yer SWOT analizi yapılarak belirlenmiş ve taşınmaz mal geliştirme projelerinde fizibilite çalışmasının önemi gösterilmeye çalışılmıştır.(Taktak \& Mehmet, 2018)

$\mathrm{Bu}$ çalışmada güneş enerjisi potansiyeli yüksek bölgelerimizden Doğu Akdeniz bölgesinde Osmaniye ili ve ilçelerinde yapılmış olan GES projeleri incelenmiştir. Arcgis programı kullanılarak, GES kurulmuş parsellerin İlçe bazlı CBS veri tabanı oluşturulmuştur. Yıllara göre ilçe bazlı, GES kurulmak suretiyle arazi kullanımda oluşan değişimler CBS kullanılarak izlenmiştir.

Taktak, Ilı ve Uyan, çalışmalarında CBS ile GES için en uygun yer tespiti yapılmaya çalışılmışken bu çalışmada GES kurulduktan sonraki arazi kullanım değişimleri enerji verimliği ile birlikte irdelenmiştir. Parsel bazlı tescilli alan verileri ile enerji dağıtım şirketinden alınan proje kurulu güç bilgileri konumsal olarak CBS verisine dönüştürülmüştür.

Yapılan çalışma ile Osmaniye ilindeki GES kurulumu yapılabilecek arazilerin büyüklük olarak ildeki potansiyele göre çok az olduğu görülmektedir. GES kurulumu yapılırken arazilerin şekli bozuklukları GES verimliliğini düşürmektedir. GES kurulumu yapılan parseller kadastro parseli olduğu için 
düzensizdir. Yine yapılan çalışmalara göre kıraç arazi için Osmaniye ilinde elde edilen tarımsal gelirin, GES tesisinden elde edilecek kira gelirine göre çok düşük olduğu belirlenmiştir. Tarım il müdürlüğünden alınan veriler ışığında kıraç arazinin dekarının yıllık tarımsal geliri 172,46 TL iken GES geliri 1500 TL'dir.

\section{Materyal ve Metot}

\subsection{Türkiye'de Güneş Enerjisi}

Coğrafi konumu açısından, Türkiye önemli güneşlenme potansiyeline sahiptir. Y1l boyunca yaklaşık 2.738 saat güneşlenme yapılmaktadır. 2017 yılında yaklaşık 823.000 TEP 1S1 enerjisini üretilmiş ve 20 milyon metrekarelik güneş kollektör alanına ulaşmıştır.

2017 y1lında konutlarda 528.000 TEP, endüstriyel alanlarda 283.000 TEP 1sı enerjisi tüketildiği hesaplanmıştır. (URL-1) 2017 yılı sonunda lisanslı ve lisanssız güneş enerjisi santrali santralleri sayısı 3.616 hesaplanırken, işletmedeki bu santrallerin toplam kurulu güç miktarı 3.421 MW'a ulaşmıştır. Türkiye'de son yıllarda güneş enerjisi kurulu gücü açısından karşılaştırma yapıldı̆̆ında 2016'da 249 MW, 2015'te 832,5 olan ve büyük bir gelişme göstererek 2017'de 3.421 MW'a yükseldi.(URL-1)

Türkiye, güneş enerjisi potansiyeli açısından diğer birçok ülkeye göre bir avantajdır. Çünkü coğrafi konumu sayesinde yüksek güneş enerjisi potansiyeli elde edebilir. Türkiye yıl boyunca yaklaşık 2 bin 738 saat güneşlenme süresi hesaplanmaktadır. 2017 yılı sonunda toplam lisanslı ve lisanssız santral sayısı 3016 olarak hesaplanmıştır.(URL-2)

\subsection{Osmaniye'de Güneş Enerjisi}

$3.767 \mathrm{~km}^{2}$ yüzölçümüne sahip olan Osmaniye arazisinin $\% 42$ 'si orman alan1,\%39'u ekili ekili tarım alanı,\%17'si tarıma elverişsiz arazi ve\%2'si diğer arazilerden oluşmaktadır. İl merkezi deniz seviyesinden $118 \mathrm{~m}$ yüksekliktedir. Osmaniye'nin iklimi dağlık ve ovalık alanlarda farklılık göstermekle birlikte tipik Akdeniz iklimi özellikleri gösterir. Yazlar sıcak ve kurak, kışlar ılık ve yağışlıdır.

2010 TÜİK verilerine göre ilde merkez ilçe ile birlikte 7 ilçe, 9 belde ve 161 köy bulunmaktadır. Osmaniye ilinin ilçeleri; Bahçe, Düziçi, Hasanbeyli, Kadirli, Sumbas ve Toprakkale.

Ceyhan Nehri'nin Osmaniye'den geçip Akdeniz'e dökülmesine ayrı bir önem katıyor. Ceyhan Aslantaş Barajı üzerinde Türkiye'nin en yüksek barajı olan ve enerji ve tarımsal sulamaya önemli faydalar sağlayan Berke Barajı. Ayrıca Türkiye'nin en büyük kurulu rüzgâr santrali Bahçe ve Hasanbeyli ilçelerinden Gökçedağ RES (Rüzgâr enerjisi santrali) de y1lda 500 milyon kwh elektrik üretilmektedir.

Osmaniye, uzun güneşlenme süreleri ve rüzgâr enerjisi potansiyeli ile yenilenebilir enerji kaynakları açısından oldukça avantajlı bir konuma sahiptir. Osmaniye'deki rüzgâr santralleri 2009 yılından beri aktif olarak işletilmektedir.

Ülkemizde Akdeniz Bölgesi, güneş enerjisi potansiyeli açısından Güneydoğu Anadolu Bölgesi'nden sonra ikinci sırada yer almaktadır. Osmaniye'nin güneş radyasyonu değerinin genel olarak 1650 - $1900 \mathrm{kwh} / \mathrm{m}^{2} /$ yıl aralığında olduğu görülmektedir. Türkiye'nin toplam güneşlenme süresi yıllık ortalama 2.640 saat / y1l iken, günlük ortalama 7.2 saattir. Osmaniye toplam y1llik ortalama 2861 saat / y1l güneşlenme süresi ve Osmaniye'de ortalama günlük güneşlenme süresi 7,8 saat ile Türkiye ortalamasının üzerindedir. Osmaniye ili Türkiye Elektrik Üretiminin \%0.88'ini gerçekleştirmektedir. Dört Rüzgâr Santrali - Y1llık enerji üretim kapasitesi 265,3 MW ,Onaltı HES - Y1llık elektrik üretim kapasitesi 815,44 MW 2 GES - Y1llı üretim kapasitesi 4,10 MW, Bir Biyogaz Santrali - Yıllık üretim kapasitesi 3,12 MW Lisanslı ve Lisanssız Toplam Kurulu Güç 1.087,96 MW. Kurulu Güç olarak ülke toplamının\%1,29'u Osmaniye'de bulunmaktadır.(URL-4)

Toprak Koruma ve Arazi Kullanımı Kanunun 3. maddesine göre GES için kullanılabilecek olası arazinin toprak, toprak derinliği, taşlık, topografya, eğim ve tarımsal potansiyel açısından değerlendirilmesi ve herhangi bir durumun olup olmayacağı çevredeki tarım arazilerinin tarımsal kullanım bütünlügünü bozacak, "tarım arazisi", "özel mahsul arazisi", "ekili tarım arazisi", "sulu tarım arazisi" veya "marjinal tarım arazisi" olarak tanımlanmalıdır.(URL-3) Tarım Arazilerinin Korunması, Kullanılması ve Arazi Toplulaştırılmasına İlişkin Yönetmelik uyarınca Mutlak tarım arazileri, Özel mahsul arazileri, Dikili tarım arazileri, Sulanan tarım arazileri, çevre arazilerin tarım bütünlügünü bozan alanlar için GES başvurusu alınmamaktadır. $\mathrm{Bu}$ nedenle zemin yapısının ve sınıfının doğru belirlenmesi esastır.

Toplam tarım alanı 1,2 milyon dekardır. Tarım arazilerine ek olarak GES yatırım alanı olarak kullanılamayan bir diğer arazi kullanımı da aktif veya bozuk orman alanlarıdır. Osmaniye'nin toplam arazi varlığının $\% 48$ 'i ağaçlık veya baltalık, bozuk veya normal ormanlarla kaplıdır. (URL-4)

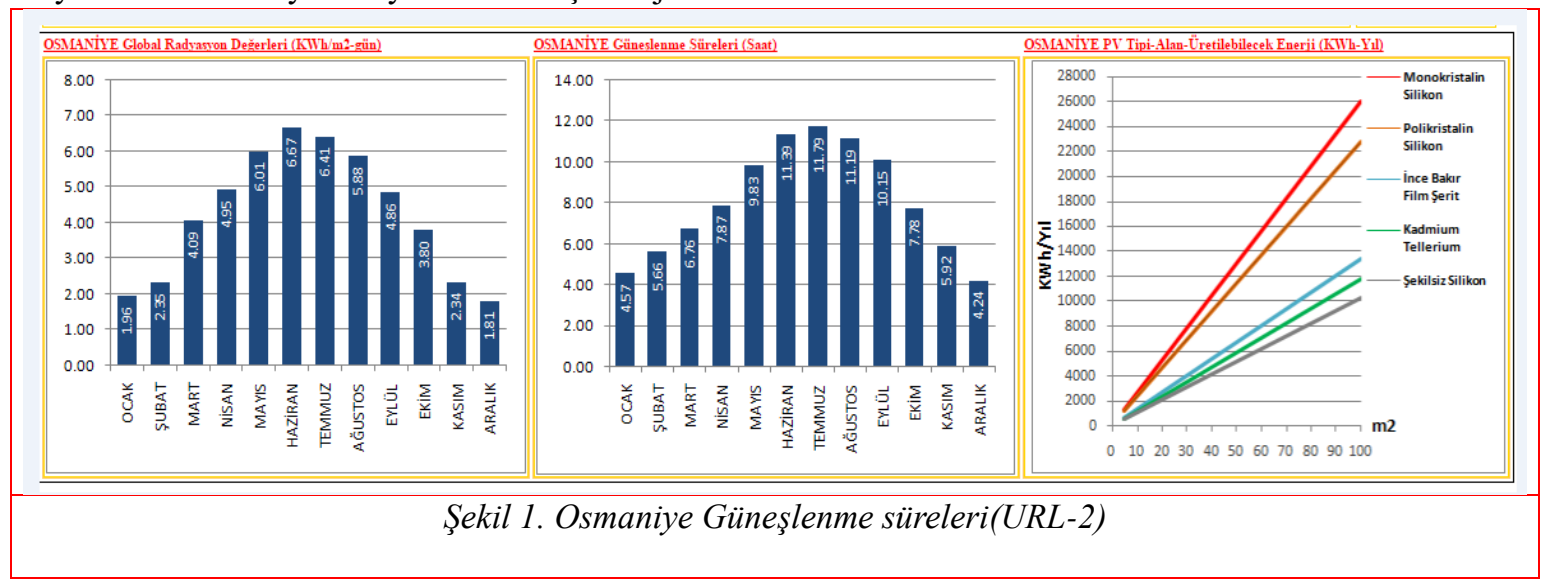


Tablo 2. Osmaniye'de tarım ve Ormanlık alanların dağllımı (URL-4)

\begin{tabular}{|c|c|c|c|c|c|c|c|c|c|c|c|c|}
\hline \multicolumn{3}{|c|}{ KORU } & \multicolumn{3}{|c|}{ BATAKLIK } & \multicolumn{3}{|c|}{ TOPLAM } & $O T$ & $\begin{array}{l}\text { ORMANS } \\
I \\
Z\end{array}$ & TOPLAM & $Y \ddot{U Z D E}$ \\
\hline Normal & Bozuk & Toplam & Normal & Bozuk & Toplam & Normal & Bozuk & Toplam & 7.33 & 167.337 & 319.913 & 48 \\
\hline 84.188 & 26.764 & 110.882 & 3.275 & 38.418 & 41.694 & 87.394 & 65.182 & 152.576 & & & & \\
\hline
\end{tabular}

\subsection{Arcgis Yardımıyla Veri Tabanı Oluşturulması}

Harita Genel Müdürlüğü web sitesi üzerinden Türkiye Mülki İdare Sınırları haritası indirilmiştir. İndirilen bu harita ArcGIS 10.6 yazilımında "Raster to Polygon" ArcToolbox komutu ile vektör veri modeline dönüştürülmüştür. Daha sonra vektör veriye dönüştürülmüss katman "Clip" ArcToolbox komutuyla Osmaniye il sınırından kesilerek Osmaniye İlçeler haritası elde edilmiştir. Elde edilen harita geodatabase (gdb) formatında saklanarak CBS veri tabanı oluşturulmuştur.

\subsection{Tarım Arazilerinde Verimlilik Tespiti}

Osmaniye Gıda Tarım ve hayvancılık müdürlüğünden alınan veriler 1 şı ğında taban ve kıraç arazi için tarla için yapılan harcamalar (ekim, gübreleme, hasat vb.) giderleri tabloda 2019 yılı buğday üretimi için gösterilmiştir.

Tablo 3'te Osmaniye merkez ilçe 2019 y1lı kıraç arazi buğday ekim masraf ve gelir durumu gösterilmiştir. Tarım İl müdürlüğünden alınan verilere göre, kıraç arazide yetiştirilen buğday ürününün masraf unsurları 2019 yılı fiyatlarıyla belirtilmiştir. Masraf unsurları ; toprağın hazırlanması, ekim, gübreleme, ilaçlama, hasat ve pazarlama ve yan ürün maliyeti (balya) gibi ek kalemler halinde gösterilmiştir. Buna göre toplam üretim masrafları 616,14 TL dir.Net kar için dekar başına 32,46 TL gelir hesaplanmıştır. Arazinin kiralanarak kullanıldığı değerlendirilmiştir.

Verimlik değerlendirmesinin yapılmasının ana nedeni GES tesisleriyle kıyaslayabilmek içindir.

\section{Araştırma Sonuçları ve Tartışma}

\subsection{Arcgis Yardımıyla Veri Tabanı Oluşturulması}

\subsection{1 Üretimin Yıllara Göre Değgişimin İşlenmesi}

Elektrik dağıtım şirketinden alınan 2016-2019 yılları arası GES üretim verileri oluşturduğumuz CBS veri tabanına işlenmiş ve bu veriler yardımı ile 2016-2019 yılları için GES üretimini gösteren tematik haritalar Arcgis 10.6 yazılımı ile üretilmiştir.

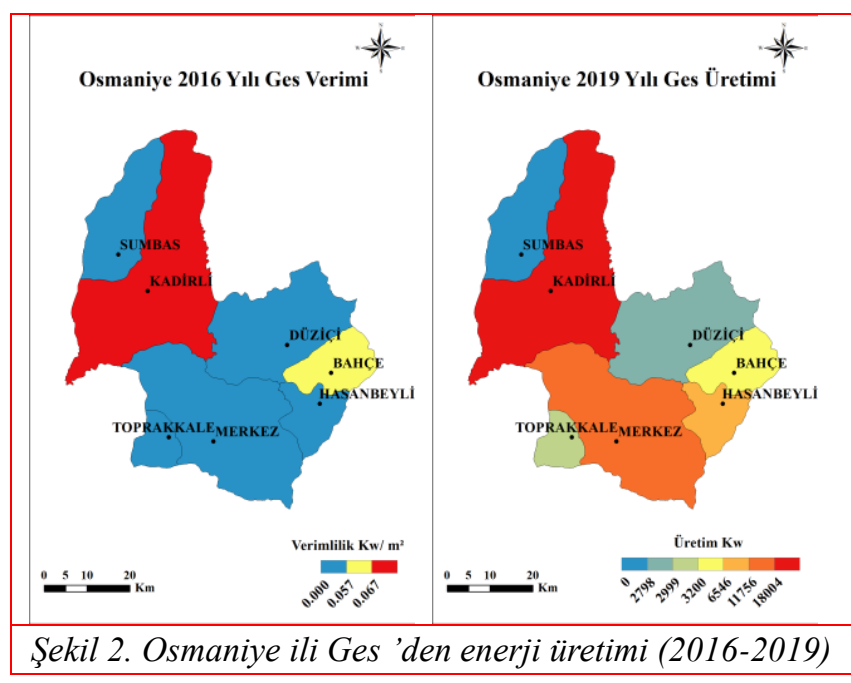

Renk skalasına bakıldığında mavi renk en az GES kurulu gücünün olduğu ilçeyi koyu kırmızı da en fazla kurulu gücün olduğu ilçeyi göstermektedir.2016'dan 2019'a doğru gittikçe GES kurulumun artığı da renk skalasına bakıldığında belirgin olarak gözükmektedir.2016 yılında Sumbas, Toprakkale ,Hasanbeyli, Düziçi ve merkez ilçelerde GES den enerji üretimi yokken, 2019 yılında en fazla merkez ilçede olmak üzere ,Düziçi , Toprakkale ve Hasanbeyli ilçelerinde GES den enerji üretimi artmıştır.

Elektrik dağıtım şirketinden alınan veriler 1şı̆̆ında Osmaniye ili ve ilçelerinde kurulmuş GES den enerji üretim miktarları, ilçe bazında 2016'dan 2019'a kadar yıllık olarak gözükmektedir. Bu verilere göre Sumbas ilçesinde henüz GES kurulumu bulunmamakta olup en fazla GES kurulumu 18.004,230 mw ile Kadirli ilçesindedir.

Tablodaki veriler Arcgis 10.6 programı yardımıyla CBS veri tabanına işlenmiş ve 2016-2019 yılları için GES den enerji üretimini gösteren tematik haritalar üretilmiştir.

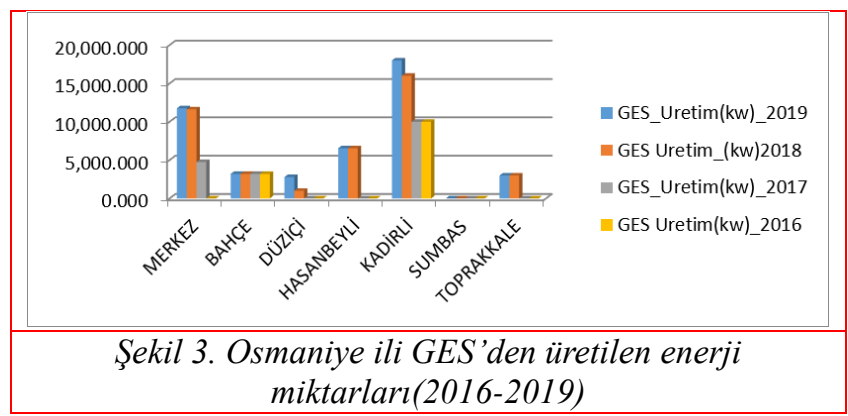


Tablo 3. Osmaniye Kıraç arazi buğday ekim masraf gelir durumu

\begin{tabular}{|c|c|c|c|c|c|c|c|}
\hline Ürün adı & BUĞDAY & \multicolumn{3}{|l|}{ YIL } & \multicolumn{3}{|c|}{2019} \\
\hline$\dot{I L}$ & OSMANIYE & \multicolumn{3}{|c|}{ Toplam işletme arazisi } & \\
\hline$\dot{I} L C ̧ E$ & MERKEZ & \multicolumn{3}{|c|}{ Buğday yetiştiriciliği Alan } & \multicolumn{3}{|c|}{ KIRAÇ ARAZI } \\
\hline$K \ddot{O Y}$ & & \multicolumn{3}{|c|}{ Anketör } & & & \\
\hline \multirow{2}{*}{\multicolumn{2}{|c|}{ Masraf unsurlart }} & \multirow{2}{*}{$\begin{array}{l}\text { Yapıla } \\
n \\
\text { işleml } \\
\text { erin } \\
\text { adl }\end{array}$} & \multirow{2}{*}{ 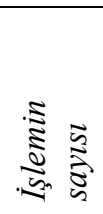 } & \multirow[t]{2}{*}{$\begin{array}{l}\text { Kullanilan } \\
\text { ekipman/materyal } \\
\text { adl }\end{array}$} & \multicolumn{2}{|c|}{$\begin{array}{l}\text { Kullanilan } \\
\text { materyalin }\end{array}$} & \multirow[t]{2}{*}{$\begin{array}{l}\text { Masrafların } \\
\text { toplamı }\end{array}$} \\
\hline & & & & & $\begin{array}{l}\text { Fiyatt } \\
(T l / k g)\end{array}$ & \begin{tabular}{|l|} 
Miktarl \\
$(\mathrm{Kg} / \mathrm{da})$
\end{tabular} & \\
\hline \multirow{3}{*}{$\begin{array}{l}\text { A)Toprak } \\
\text { hazırlı̆̆ğ }\end{array}$} & $\begin{array}{l}\text { Toprak işleme } 1 . \\
\text { işlem }\end{array}$ & $\begin{array}{l}\text { 1. } \\
\text { sürüm }\end{array}$ & 1 & Pulluk & & & 35.00 \\
\hline & $\begin{array}{l}\text { Toprak işleme } 2 . \\
\text { işlem }\end{array}$ & $\begin{array}{l}2 . \\
\text { sürüm }\end{array}$ & 1 & Goble Diskano & & & 20.00 \\
\hline & $\begin{array}{l}\text { Toprak işleme } 3 . \\
\text { işlem }\end{array}$ & $\begin{array}{l}\text { slkıştır } \\
\text { ma }\end{array}$ & 1 & Tapan & & & 10.00 \\
\hline \multirow{3}{*}{ B) Ekim } & Ekim & & & Mibzer & & & 15.00 \\
\hline & Tohum Bedeli & & & & 1.90 & & 57.00 \\
\hline & Taban gübresi & & & $20-20-O$ & 1.85 & & 55.50 \\
\hline \multirow{4}{*}{ C) Gübreleme } & Gübreleme & & 3 & S.G.M & & & 30.00 \\
\hline & Üst gübresi 1 & & & Amonyum sülfat & 1.25 & & 25.00 \\
\hline & Üst gübresi 2 & & & $\ddot{U} r e(\% 46)$ & 2.00 & & 30.00 \\
\hline & Yaprak gübresi & & & $20-20-20+Z n$ & 50.00 & & 10.00 \\
\hline \multirow[t]{3}{*}{ D) İlaçlama } & İlaçlama & & 3 & Pulvenzatör & & & 30.00 \\
\hline & İlaç 1 & & & Yabancl ot & 833.33 & & 16.67 \\
\hline & İlaç 2 & & & Pas İlacı & 150 & & 30.00 \\
\hline \multirow{2}{*}{$\begin{array}{l}\text { E) Hasat ve } \\
\text { pazarlama }\end{array}$} & Hasat ve Harman & & & Biçerdöver & & & 25.00 \\
\hline & $\begin{array}{l}\text { Tassıma ve } \\
\text { pazarlama }\end{array}$ & & & & & & 10.00 \\
\hline \multirow{2}{*}{$\begin{array}{l}\text { F) Yan ürün } \\
\text { maliyeti }\end{array}$} & Balya Maliyeti & & & Balya makinast & & & 36.00 \\
\hline & Taşıma Maliyeti & & & & & & 5.00 \\
\hline \multicolumn{2}{|c|}{$\begin{array}{l}\text { G)Değissen masraflar } \\
\text { toplami }(A+B+C+D+E+F)\end{array}$} & & & & & & 440.17 \\
\hline \multicolumn{2}{|c|}{ G 1)Sermaye faizi(\%5) } & & & & & & 22.01 \\
\hline \multicolumn{2}{|c|}{ H)Toplam değişen masraflar $(G+G 1)$} & & & & & & 462.18 \\
\hline \multicolumn{2}{|c|}{ I)Toplam sabit Masraflar $(i 1+i 2+i 3)$} & & & & & & 153.87 \\
\hline \multicolumn{2}{|c|}{ I 1) Tarla kirasl } & & & & & & 140.00 \\
\hline \multicolumn{2}{|c|}{$\dot{I}$ 2) Genel idari giderler } & & & & & & 13.87 \\
\hline İ3) Ürün sigo & & & & & & & 0.00 \\
\hline J) Toplam üret & $n$ masraflarl $(H+\dot{I})$ & & & & & & 616.14 \\
\hline K)Ana ürün ve & $\mathrm{mi}(\mathrm{kg} / \mathrm{da})$ & & & & & & 450.00 \\
\hline L) Ana ürün $s c$ & ls fiyatı $(T l / k g)$ & & & & & & 1.35 \\
\hline M) Ana ürüng & liri $(K * L)$ & & & & & & 607.50 \\
\hline N) Yan ürün $v \epsilon$ & imi(Balya) $(\mathrm{kg} / \mathrm{da})$ & & & & & & 180.00 \\
\hline O)Yan ürün sa & s fiyatı(Tl/kg) & & & & & & 0.40 \\
\hline P) Yan ürün $g$ & iri $\left(N^{*} O\right)$ & & & & & & 72.00 \\
\hline R) Gayri safi i & etim değeri $(M+P)$ & & & & & & 679.50 \\
\hline S)Ana ürün içı & yapılan masraf $(J-F)$ & & & & & & 575.04 \\
\hline T) Ana ürün iç & net $\operatorname{kar}(M-S)$ & & & & & & 32.46 \\
\hline U)Ürün maliy & $i(S / K)$ & & & & & & 1.28 \\
\hline
\end{tabular}




\subsubsection{Arazi Kullanımın Yıllara Göre Değişimin Incelenmesi}

Tapu ve Kadastro Genel Müdürlüğü (TKGM) Parsel Sorgulama Uygulaması yardımı ile Elektrik dağıtım şirketinden alınan parsel bilgilerini kullanılarak mevcut GES üretim alanları hesaplanmıştır. Parsellerin, üretime başlamadan önceki uydu görüntüleri ve şimdiki uydu görüntüleri karşılaştırma yapmak amacı ile alınmıştır. Alan verileri CBS veri tabanına işlenmiş ve bu veriler yardımı ile 2016-2019 yılları için GES kullanım alanlarını gösteren tematik haritalar ArcGIS 10.6 yazılımı ile üretilmiştir.

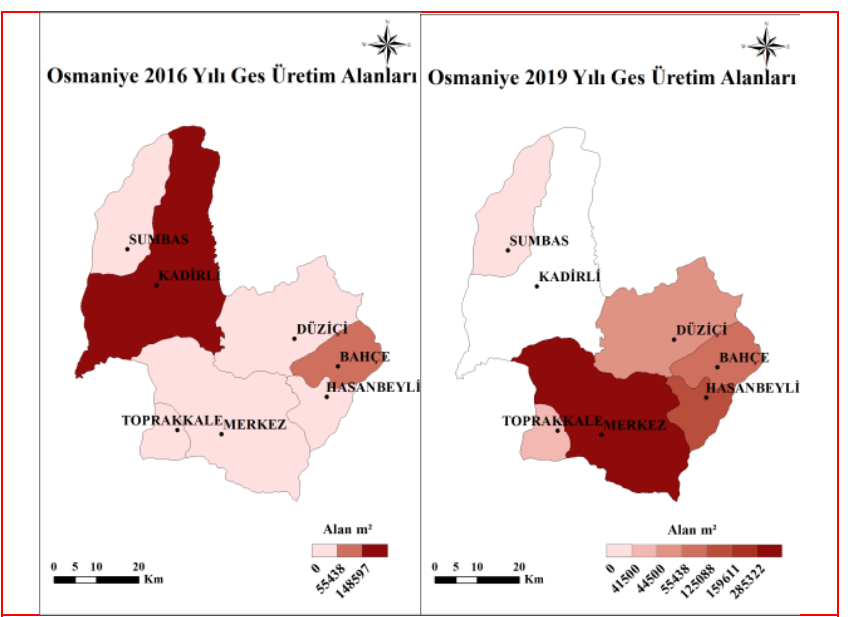

Sekil 4. Osmaniye ili GES'den üretimi alanlarl (2016 ve 2019)

GES üretim alanları $\left(\mathrm{m}^{2}\right)$ açık kahverengiden koyu kahverengine doğru renklendirilmiştir. Buna göre 2019 y1lı itibarıla en az GES kurlumu Sumbas ve Toprakkle'de iken daha sonra Düziçi , Bahçe , Hasanbeyli ,merkez ve en çok alan Kadirli ilçesinde gerçekleşmiştir.

Türkiye Elektrik Dağıtım Anonim Şirketi'nden alınan veriler 1şığında Osmaniye ilinde 2019 y1l sonu itibarıyla GES santrallerinin artarak devam ettiği görülmektedir. 2015 de ruhsat alma çalışmalarından sonra , 2016'da araziye kurulum başlamıştır. Tabloda 2019 yılı itibarıyla merkez ve diğer ilçelerde kurlumu gerçekleşen GES arazileri $\mathrm{m}^{2}$ büyüklüğünde verilmiştir.

Tablo 4. Osmaniye ve ilçelerinde yıllara göre GES kurulu

\begin{tabular}{|c|c|c|c|c|}
\hline & & & & \\
\hline fLC̣E & $2016\left(\mathrm{~m}^{2}\right)$ & $2017\left(m^{2}\right)$ & $2018\left(m^{2}\right)$ & $2019\left(\mathrm{~m}^{\prime}\right)$ \\
\hline MERKEZ & 0.00 & 60400,00 & $159.441,594$ & $159.611,594$ \\
\hline BAHÇE & $55.438,102$ & $55.438,102$ & $55.438,102$ & $55.438,102$ \\
\hline DẼziçi & 0.00 & 0.00 & $13.100,00$ & $44.500,00$ \\
\hline HASANBEYLI & 0.00 & 0.00 & $125.088,00$ & $125.088,00$ \\
\hline KADIRLII & $148.597,797$ & $148.597,797$ & $255.209,50$ & $285.322,406$ \\
\hline SUMBAS & 0.00 & 0.00 & 0.00 & 0.00 \\
\hline TOPRAKKALE & 0.00 & 0.00 & $41.500,00$ & $41.500,00$ \\
\hline
\end{tabular}

GES üretimi yapılan arazilerin alansal büyüklüğü 2016 yılında Kadirli ilçesinde $148.597,797 \mathrm{~m}^{2}$ ve Bahçe ilçesinde $56438,102 \mathrm{~m}^{2}$ de iken diğer ilçelerde henüz kurulum gerçekleşmemiştir. 2017 y1lında merkez ilçede 60400,00 m² alansal büyüklük eklenmiştir.2018 yılında merkez ilçede GES kurulumu yapılmış parsel büyüklüğü 159.441,594 $\mathrm{m}^{2}$ ye çıkmış , Düziçi ilçesi 13.100,00 $\mathrm{m}^{2}$,Hasanbeyli ilçesi $125.088,00 \mathrm{~m}^{2}$, Toprakkale ilçesi $41.500,00 \mathrm{~m}^{2}$ ve Kadirli ilçesi GES kurulum alanı 255.209,50 $\mathrm{m}^{2}$ olmuştur.2019 yılında tamamlanan GES projeleriyle merkez ilçe kurulum alanı 159.611,694 $\mathrm{m}^{2}$ ve Kadirli ilçesi 285.322,406 $\mathrm{m}^{2}$ kurulum alanına ulaşmıştır. Sumbas ilçesinde GES kurulumu bulunmazken diğer ilçeler 2018 yılıyla aynı büyüklükte kalmıştır.

\subsection{Verimlilik Analizi}

\subsubsection{GES Açısından Değerlendirme}

Şekil 5'ten anlaşılacağı üzere Osmaniye ve ilçelerinde 2019 y1lı GES tesislerinde kurulum alanlarıyla $\left(\mathrm{m}^{2}\right)$ üretim miktarları oranlanmış ve $\mathrm{m}^{2}$ ye düşen üretim miktarı bulunmuştur. $\mathrm{Bu}$ oranlar değerlendirilerek ilçe bazlı verimlilik analizi yapılmıştır.

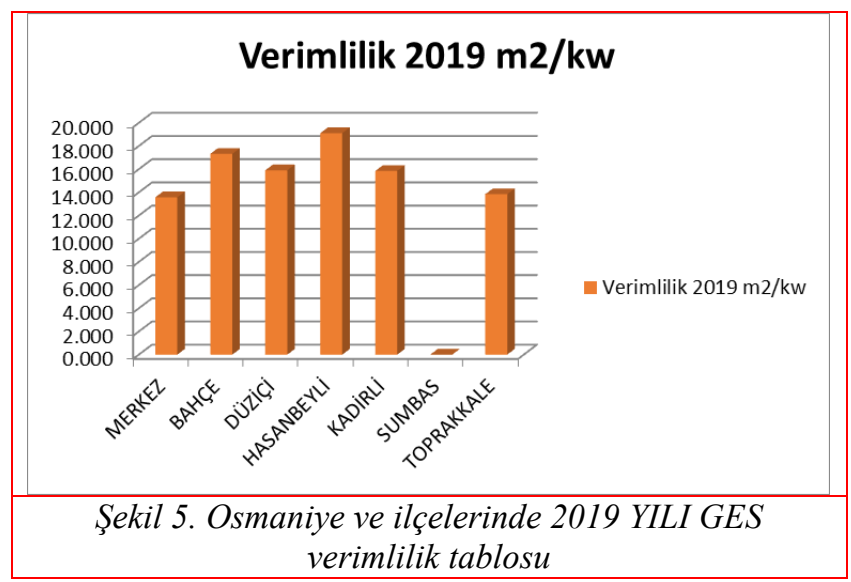

GES projeleri ilçe bazında arazi kullanımları incelenerek $\mathrm{m}^{2}$ 'ye üretilen $\mathrm{kw}$ hesaplanarak gösterilmiştir. Sumbas da GES kurulumu bulunmamaktadır. Sirayla $\mathrm{m}^{2} / \mathrm{kw}$ oran Hasanbeyli ilçesinde 19.109,Bahçe ilçesinde 17.324,Kadirli ve Düziçi ilçesinde 15.904, Kadirli ilçesinde 15.848 ,Toprakkale ilçesinde 13.837 ve en düşük oran 13.577 ile merkez ilçededir.

GES üretiminin $\mathrm{m}^{2}$ ye düşen $\mathrm{kw}$ miktarının ilçelere göre farklılık göstermesinin güneş açısı, engebe, gölgelme vb. faktörler yanında mesleğimiz açısından parsel boyutlarının ve düzgün olmayan şekillerininden kaynaklanmaktadır. Şekli bozuk olan parsellerin etrafinda birçok panel konulamayan âtıl alan kalmaktadır. Parsellerin GES kurulmadan önce ifraz gibi düzenlemelerle şekillerinin düzeltilmesi daha verimli olacaktır.

Şekil 6 da Osmaniye Merkez İlçe Sakızgediği Köyü 102 ada nolu parsel ve Düziçi İlçesi Yazlamazlı Köyü 125 ada 29 nolu parsel üzerine kurulu GES tesisi gözükmektedir. Parsellerin kenarlarında artık kısımlar kalmış bu alanlar hem tarımsal açıdan hem de GES arazisi olarak kullanılmayan âtıl alanlardır

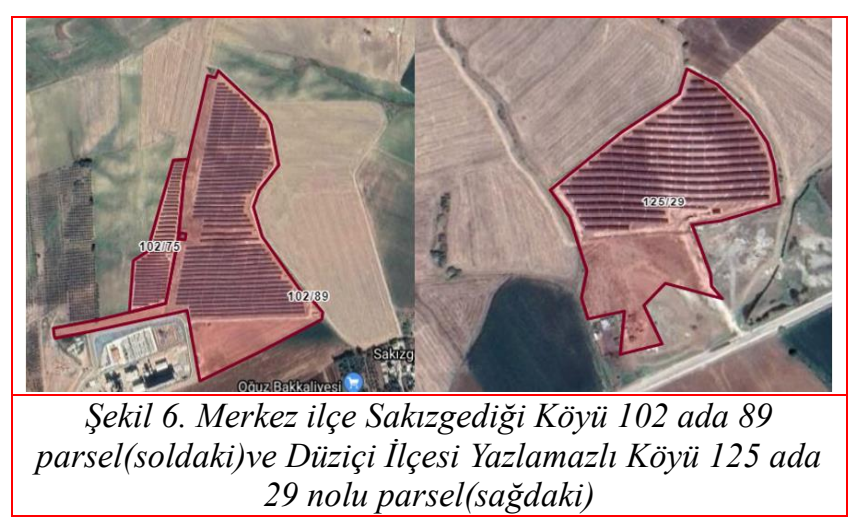




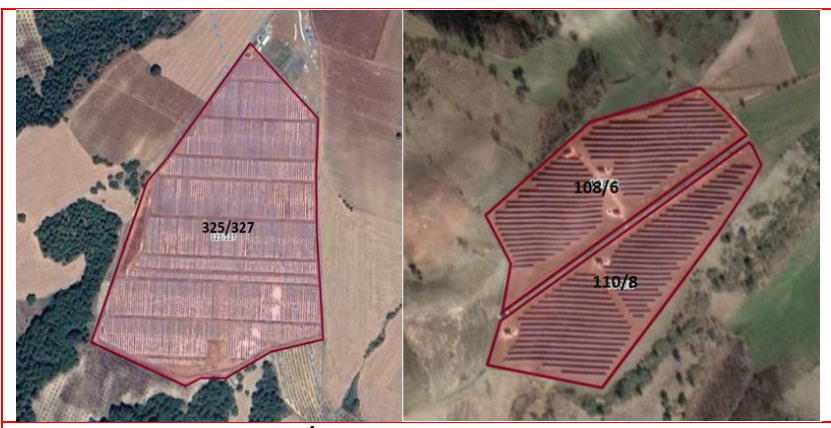

Şekil 7. Hasanbeyli İlçesi 325 ada 327 parsel (soldaki)ve Bahçe ilçesi Burgaçlı Köyü 110 ada 8 nolu parsel(săgdaki)

Şekil 7 de Hasanbeyli İlçesi 325 ada 327 parsel ve Bahçe İlçesi Burgaçlı Köyü 110 ada 8 nolu parsel üzerine kurulu GES tesisleri görünmektedir. Kurulum parseller üzerine maksimum seviyede yerleştirilmiştir. Âtıl alanlar oluşmamıştır. Sonuç olarak Hasanbeyli ve Bahçe ilçerinin GES verimliliği $\mathrm{m}^{2} / \mathrm{kw}$ olarak diğer ilçelere göre yüksektir.

\subsubsection{Tarımsal Açıdan Değerlendirme}

Osmaniye Gıda Tarım ve hayvancılık müdürlüğünden alınan veriler 1şığında buğday üretiminin, kıraç arazilerde dekara $450 \mathrm{~kg}$, taban araziler için dekara $600 \mathrm{~kg}$ olduğu anlaşılmaktadır. 2019 yılı buğday fiyatları ortalama 1.5 TL'dir. Tarım il müdürlüğünden alınan tabloya göre kıraç arazide dekara masraflar düştükten sonraki gelir 32.46 TL'dir.

2019 yılı itibarıyla Merkez ilçede 159611,594m², Bahçe'de 55438,102 $\mathrm{m}^{2}$ Düziçi ilçesinde $44500 \mathrm{~m}^{2}$, Kadirli ilçesinde $285322,406 \mathrm{~m}^{2}$, Hasanbeyli ilçesinde $125088 \mathrm{~m}^{2}$ ve Toprakkale ilçesinde $41500 \mathrm{~m}^{2}$ arazi de GES kurlumu gerçekleşmiştir.

$\mathrm{Bu}$ veriler 1şında Merkez ilçede 159,611549 dekarlık arazi için tarımsal gelir 27526.608 TL, Bahçe'de 55,438102 dekarlık arazi için 9560.855 TL, Düziçi’nde 44,5 dekarlık arazi için 7674,47 TL, Hasanbeyli 'de 125.088 dekarlık arazi için 21572.6765 TL, Toprakkale de 41.5 dekarlık arazi için 7157.09 tl ve Kadirli de 285.322406 dekarlık arazi için 49206.702 TL net tarımsal gelir elde edilmektedir. Yapılan hesaplamalarda tarla sahibi tarafindan yapılan tarımsal faaliyet olarak hesaplanmıştır.

\section{Tablo 5. Osmaniye ili kıraç arazi/GES kira gelir} karşılaştırması

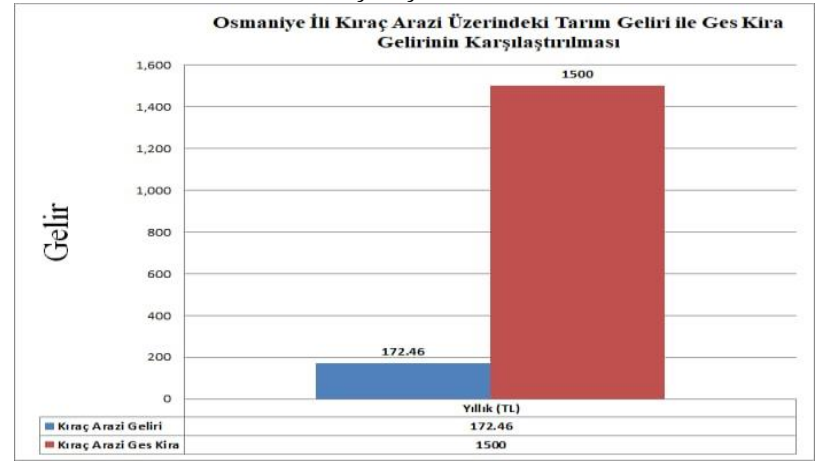

Tablo 5'ten anlaşılacağına göre arazi kullanım geliri açısından kıraç arazilerde arazi sahibinin eline geçen gelir olarak tarımsal kullanımda yıllık 172,46 TL geçerken, GES için kiraya verildiğinde 1500 TL gelir elde edilmektedir.

2019 GES kurulan arazilerin kira gelirinin dönüme $\left(1000 \mathrm{~m}^{2}\right) 1500 \mathrm{TL}$ olduğu yapılan kira anlașmalarından anlaşılmaktadır.

\section{Sonuç}

$\mathrm{Bu}$ çalışmada Osmaniye ili ve ilçelerinde kurulan GES projeleri, ilçe bazında incelenerek 2016-2019 yılları arasındaki üretimdeki değişim ( $\mathrm{kw}$ olarak) ve arazi kullanımındaki değişim ( $\mathrm{m}^{2}$ olarak) CBS yardımıyla gösterilmiștir. Ayrıca $\mathrm{m}^{2}$ ye düşen kw hesaplanarak ilçe bazında verimlilik analizi de yapılmıştır.

Yapılan verimlilik analizine göre arazi kullanımı açısından $\mathrm{m}^{2} / \mathrm{kw}$ oranında Osmaniye ve ilçeleri değerlendirildiğin de en verimli ilçenin 19.109 ile Hasanbeyli İlçesi olduğu belirlenmiştir.

GES kurulu arazilerde şekli bozuk olan parsellerde panel yerleştirmek sıkıntılı olmaktadır. Mülkiyet bazlı kiralama olduğundan parseller kadastro parseli olarak kurulum yapılmaktadır. Bunun yerine parseller de sinır düzenlemeleri yapılarak daha düzgün şekilli parseller oluşturulursa, panel yerleştirmeleri daha uygun olacak, âtıl arazi oluşmayacak ve verimlilik artacaktır.

Osmaniye ilinin yüzölçümü $3767 \mathrm{~km}^{2}$ olup \%17 si tarıma elverişsiz arazidir. Osmaniye ilindeki tarıma elverişsiz arazi yaklaşık $640 \mathrm{~km}^{2}$ 'dir. Ayrıca mevcut GES kurulu arazi büyüklüğü $0.711 \mathrm{~km}^{2}$ 'dir. Potansiyel düşünüldüğünde kurulumun yetersiz olduğu gözükmektedir.

GES kurulması durumunda tarımsal olarak verimsiz ve az gelir getiren kıraç arazi sahipleri çok daha fazla gelir elde edebileceklerdir. Mevcut GES kurulan arazilerin yılık tarımsal gelirlerine göre GES ten elde ettikleri kira geliri çok daha yüksektir. Tarımsal kullanım açısından bakıldığında kıraç arazi için tarımsal gelirin GES gelirini göre çok düşük olduğu tespit edilmiştir.

\section{Kaynakça}

AKBULAK, C., ERGINAL, A. E., \& ÖZTÜRK, B. (2008). Gelibolu Yarımadası'nın kuzeybatı kıyılarında arazi kullanımının uzaktan algılama ile incelenmesi. Selçuk Üniversitesi Sosyal Bilimler Enstitüsü Dergisi(20), 41-50.

Bahnemann, D. (2004). Photocatalytic water treatment: solar energy applications. Solar energy, 77(5), 445-459.

Dewan, A. M., \& Yamaguchi, Y. (2009). Land use and land cover change in Greater Dhaka, Bangladesh: Using remote sensing to promote sustainable urbanization. Applied Geography, 29(3), 390-401.

Fatih, K., \& Karatepe, A. (2012). UZAKTAN ALGILAMA TEKNOLOJILERİ İLE BEYKOZ İLÇESİ (1986-2011) ARAZI KULLANIMI DEĞİȘIM ANALİŻ. Marmara Coğrafya Dergisi(25), 378-389.

GEYMEN, A. (2016). Coğrafi Bilgi Sistemleri kullanılarak su havzalarındaki doğal kaynakların izlenmesi: Elmalı Havzası örneği. KSÜ Doğa Bilimleri Dergisi, 19(2), 174180.

Güçlüer, D., \& Batuk, F. (2011). Güneş Enerjisi Santrali Kurulacak alanların CBS-ÇÖKA Yöntemi ile Belirlenmesi. TMMOB Harita ve Kadastro Mühendisleri 
Odası, 13. Türkiye Harita Bilimsel ve Teknik Kurultayl, Ankara.

Gürbüz, M., Denizdurduran, M., Karabulut, M., \& Kızılelma, Y. (2012). Uzaktan alg1lama ve CBS kullanarak Elbistan Ovasında arazi kullanımı/arazi örtüsünde meydana gelen değişimlerin incelenmesi. KSÜ Mühendislik Bilimleri Dergisi, 30-37.

Karagöl, E. T., \& Kavaz, İ. (2017). Dünyada ve Türkiye'de yenilenebilir enerji. Analiz. Seta, 197, 18-28.

Kaya, Ö., \& Toroğlu, E. (2015). Monitoring urban development of Kayseri and change detection analysis. Türk Coğrafya Dergisi, 65, 87-96.

Kern, J., \& Trieb, F. (2015). BETTER-Bringing Europe and Third Countries closer together Through Renewable Energies A Framework for successful RES-E Expansion in NA.

KOCA, H., \& UZAR, M. CBS VE BULANIK ANALITIK HIYYRARŞİ PROSESİ İLE GÜNEŞ ENERJI SANTRALLERININ YERLERININ BELIRLENMESİ: MENEMEN ÖRNEĞİ.

Komitesi, D. E. K. T. M. (2009). Dünya'da ve Türkiye'de Güneş Enerjisi. EKC Form Ofset, ISBN, 978-605.

Mevlüt, U. (2017). Güneş enerjisi santrali kurulabilecek alanların AHP yöntemi kullanılarak CBS destekli haritalanmas1. Pamukkale Üniversitesi Mühendislik Bilimleri Dergisi, 23(4), 343-351.

Sánchez-Lozano, J. M., Teruel-Solano, J., Soto-Elvira, P. L., \& García-Cascales, M. S. (2013). Geographical Information Systems (GIS) and Multi-Criteria Decision Making (MCDM) methods for the evaluation of solar farms locations: Case study in south-eastern Spain. Renewable and sustainable energy reviews, 24, 544-556.

SARSICI, N. (2020). Karabük ilinde Güneş Enerjisi Santrali (GES) Kurulabilecek Alanların Çok Ölçütlü Karar Analizi ile Tespiti

Shalaby, A., \& Tateishi, R. (2007). Remote sensing and GIS for mapping and monitoring land cover and land-use changes in the Northwestern coastal zone of Egypt. Applied Geography, 27(1), 28-41.

Şahin, A. (2009). 1. Türkiye Güneş Enerjisi Kursu. TMMOB Meteoroloji Mühendisleri.

Tahri, M., Hakdaoui, M., \& Maanan, M. (2015). The evaluation of solar farm locations applying Geographic Information System and Multi-Criteria Decision-Making methods: Case study in southern Morocco. Renewable and sustainable energy reviews, 51, 1354-1362.

Taktak, F., \& Mehmet, I. (2018). Güneş Enerji Santrali (GES) Geliştirme: Uşak Örneği. Geomatik, 3(1), 1-21.

URL-1. 2016 Yll Ham Petrol ve Doğal Gaz Sektör Raporu. Retrieved 19.03.2018 from www.tpao.gov.tr/tp5/docs/rapor/sektorrapor3105.pdf

URL-2. Enerji ve Tabi Kaynaklar Bakanliğl (2016) Yenilenebilir Enerji Genel Müdürlüğü, "Yenilenebilir Enerji,". $\quad$ Retrieved 19.03.2018 from www.eie.gov.tr/yenilenebilir.aspx

URL-3. Tarım ve Köy Işsleri Bakanlığı, 5403 Toprak Koruma ve Arazi Kullanımı Kanunu. Retrieved 01.06.2016 from

URL-4. Osmaniye İli FV Güneş Elektriği Fizibilite Çalışması. Retrieved 16.02.2021 from https://www.dogaka.gov.tr/dokuman-merkezi/arastirmave-planlama/osmaniye-ili-fv-gunes-elektrigi-fizibilitecalismasi
Varınca, K. B., \& Varank, G. (2005). Güneş kaynaklı farklı enerji üretim sistemlerinde çevresel etkilerin kıyaslanması ve çözüm önerileri. Güneş Enerjisi Sistemleri Sempozyumu ve Sergisi, İçel, 24-25.

Watson, J. J., \& Hudson, M. D. (2015). Regional Scale wind farm and solar farm suitability assessment using GISassisted multi-criteria evaluation. Landscape and urban planning, 138, 20-31.

Winston, R., \& Hinterberger, H. (1975). Principles of cylindrical concentrators for solar energy. Solar energy, 17(4), 255-258.

Wu, Q., Li, H.-q., Wang, R.-s., Paulussen, J., He, Y., Wang, M., Wang, B.-h., \& Wang, Z. (2006). Monitoring and predicting land use change in Beijing using remote sensing and GIS. Landscape and urban planning, 78(4), 322-333.

YALÇIN, C., \& Mustafa, Y. (2019). Burdur'da Güneş Enerjisi Santrali (GES) Yatırımına Uygun Alanların CBS Yöntemiyle Tespiti. Geomatik, 5(1), 36-46. 